Al Qalam: Jurnal Ilmiah Keagamaan dan Kemasyarakatan

https://jurnal.stiq-amuntai.ac.id/index.php/al-qalam

P-ISSN: 1907-4174; E-ISSN: 2621-0681

DOI : 10.35931/aq.v16i2. 897

\title{
PENINGKATAN EKSISTENSI BUDAYA ISLAMOFOBIA DALAM KEHIDUPAN MASYARAKAT KOREA SELATAN (STUDI KASUS : TINDAKAN PENOLAKAN MASYARAKAT SETEMPAT TERHADAP PEMBANGUNAN MASJID)
}

\author{
Anggi Putri*, Hardi Alunaza*, Desy Nur Shafitri*, Annisa Ernianda* \\ Fakultas Ilmu Sosial dan Ilmu Politik, Universitas Tanjungpura \\ Koresponden Email: hardi.asd@fisip.untan.ac.id
}

\begin{abstract}
Abstrak
Masyarakat beragama Islam sebagai kaum minoritas di Korea Selatan akhir-akhir ini terus menerima ujaran kebencian dari warga sekitar. Penolakan terhadap ajaran dan budaya Islam membuat masyarakat setempat memblokir eksistensi Muslim di Korea Selatan. Salah satunya terjadi ketika warga berbondongbondong menolak pembangunan masjid di daerah Daegu, Korea Selatan. Diketahui penduduk setempat membuat petisi sehingga pemerintah setempat menghentikan pembangunan masjid tersebut. Penolakan masjid di tengah pembangunan juga dipicu oleh masyarakat Korea Selatan yang tidak suka ada fasilitas keagamaan seperti gereja atau masjid di pemukiman penduduk. Dalam meneliti isu yang diangkat, penulis akan membagi fokus pembahasan menjadi 3 bagian yaitu pemaparan penulis mengenai awal mula masuknya Islam ke Korea Selatan, kemudian penulis akan melanjutkan pembahasan mengenai sentimen Islamofobia dalam tatanan masyarakat Korea Selatan terhadap Umat Muslim dan diakhiri dengan pembahasan mengenai eksistensi dari Islamofobia di Korea Selatan saat ini dengan lebih khusus melihat ke dalam satu studi kasus yaitu mengenai penolakan pembangunan Masjid oleh penduduk setempat di daerah Daegu, Korea Selatan. Penelitian ini dilakukan dengan menggunakan metode penulisan deskriptif dan jenis penelitian kualitatif. Hasil penelitian menunjukkan bahwa eksistensi dari Islamofobia di Korea Selatan kini terbilang meningkat sebab didapati "Kebijakan Diskriminatif" terhadap hak Umat Islam sebagaimana permasalahan yang terdapat pada studi kasus yang dilakukan oleh penulis.

Keyword: Budaya Islamofobia, Korea Selatan, Pluralisme Agama
\end{abstract}

\section{PENDAHULUAN}

Mendengar istilah Islamofobia, maka hal ini juga akan merujuk kepada kegagalan pluralisme di suatu negara. Pluralisme yang seharusnya dapat dijalankan oleh negara dengan memandang positif setiap perbedaan dan keberagaman sebagai kenyataan dalam kehidupan berbangsa dan beragama, dapat dikatakan gagal diimplementasikan dengan baik jika terjadinya diskriminasi terhadap dimensi-dimensi perbedaan dalam bangsa termasuk perbedaan agama yang dianut oleh setiap individu. Pluralisme tidak hanya pengakuan terhadap perbedaan atau keberagaman dalam suatu bangsa, namun pada dasarnya pluralisme juga berkenaan dengan hak

Al Qalam: Jurnal Ilmiah Keagamaan dan Kemasyarakatan Vol. 16, No. 2 Maret - April 2022 
Anggi Putri, Hardi Alunaza, Desy Nur Shafitri, Annisa Ernianda : Peningkatan Eksistensi Budaya Islamofobia Dalam Kehidupan Masyarakat Korea Selatan (STudi Kasus : Tindakan Penolakan Masyarakat Setempat Terhadap Pembangunan Masjid)

hidup dari suatu kelompok yang berada di tempat yang sama dengan suatu komunitas sebab esensi dari pluralisme juga berkenaan dengan hal-hal politik, ekonomi, sosial, dan lain sebagainya. ${ }^{1}$

Banyak negara saat ini menyatakan bahwa dirinya adalah salah satu negara yang demokrasi, akan tetapi dalam tatanan yang dijalankan oleh negara tersebut pluralisme masih menjadi hal yang sangat diperhitungkan dan cukup sulit untuk diterima bagi warga negaranya sendiri. Hak-hak yang seharusnya diperoleh melalui demokrasi tersebut dalam bentuk kedaulatan rakyat akan didukung oleh suatu otoritas dan seperangkat hukum. Adapun negara yang menyatakan diri sebagai negara demokrasi tentunya harus memenuhi prinsip-prinsip dasar dari demokrasi tersebut, yaitu Kebebasan, Kekuasaan, Keadilan, Hukum, Perwakilan, Ketertiban, Hak-hak dan Egalitarianisme. ${ }^{2}$ Untuk dapat mewujudkan setiap prinsip ini tentunya negara memiliki peran yang besar untuk mengintervensi agar implementasi dari konsep-konsep persamaan dalam upaya perwujudan HAM dapat terealisasikan bagi seluruh warga negaranya.

Realitas perbedaan agama adalah hal krusial yang memang lebih sensitif dibandingkan keberagaman lainnya. Suatu negara dapat dikatakan negara demokrasi jika tatanan dalam negara tersebut memiliki pemimpin yang dapat mengatur dan menata kehidupan warga negaranya dengan baik dan lancar tanpa adanya gejolak, utamanya dalam perbedaan agama, karena pada dasarnya hal ini dapat menjadi tolak ukur dari kualitas demokrasi suatu negara dalam menjamin hak-hak yang dapat diperoleh oleh setiap warga negara. Di samping itu, warga negara juga harus mematuhi regulasi maupun undang-undang dari negaranya sendiri agar kebebasan yang ingin didapatkan dapat dijamin dan diakui sehingga dalam kehidupan sosial yang dijalankan akan lebih adil sesuai dengan keamanan, nilai-nilai agama, moral yang berlaku serta ketertiban umum dalam tatanan negara yang demokratis.

Islamofobia sering diartikan sebagai permusuhan tidak berdasar kepada Islam dan ajarannya atau dapat dikatakan kelompok yang anti akan Islam. Kelompok ini biasanya memberikan ujaran kebencian dan tindakan diskriminasi tidak adil kepada individu dan komunitas beragama Islam. Islamofobia dapat terjadi pada individu maupun kepada kelompok-kelompok besar di suatu wilayah. Islamofobia juga dikategorikan pada tindakan permusuhan yang diterima dalam kehidupan sehari-hari baik berupa perkataan kebencian dan diskriminasi pekerjaan kepada Muslim. Islamofobia juga menimbulkan prasangka buruk terhadap Islam dan Muslim dimana

\footnotetext{
${ }^{1}$ Hendri Masduki. (2016). Pluralisme Dan Multikulturalisme Dalam Perspektif Kerukunan Antar Umat Beragama (Telaah Dan Urgensinya Dalam Sistem Berbangsa Dan Bernegara). DIMENSI-Journal of Sociology, 9(1), 16.

${ }^{2}$ Ibid, hal 18.
}

Al Qalam: Jurnal Ilmiah Keagamaan dan Kemasyarakatan Vol. 16, No. 2

Maret - April 2022 
Anggi Putri, Hardi Alunaza, Desy Nur Shafitri, Annisa Ernianda : Peningkatan Eksistensi Budaya Islamofobia Dalam Kehidupan Masyarakat Korea Selatan (STudi Kasus : Tindakan Penolakan Masyarakat Setempat Terhadap Pembangunan Masjid)

mereka akan dikucilkan oleh orang-orang lain dan dianggap sebagai minoritas yang mengganggu. ${ }^{3}$

Merebaknya budaya Islamofobia saat ini diyakini berasal dari negara-negara Barat, terlebih ketika terjadinya pengeboman di Gedung WTC New York, diyakini banyak negaranegara lain mulai terpengaruh dan ikut menerapkan budaya ini. Umat Islam dijadikan sebagai sasaran utama dari penyebab kejadian tersebut, sehingga pasca terjadinya tragedi seruan terhadap terorisme yang ditujukan terhadap Umat Islam mulai dibesar-besarkan, sehingga banyak akhirnya pandangan buruk mulai dilayangkan kepada Umat Islam di seluruh dunia. Stereotip yang dibangun dalam media negara-negara Barat terhadap Umat Muslim mengarah kepada kesan yang radikal, anti perdamaian dan acap kali mengusut kejahatan seperti kekerasan dan lain sebagainya. Banyak anggapan yang mulai menyatakan bahwa setiap Muslim adalah Umat yang menganut Islam konservatif sehingga tidak bisa dipungkiri eksistensi Islamofobia semakin tinggi seiring berjalannya waktu. ${ }^{4}$

Stereotip buruk dari setiap tuduhan yang ditujukan kepada Umat Islam atas praduga yang sangat terlihat diskriminatif tersebut membuat stigma negatif dalam cakupan dunia internasional mengenai agama Islam itu sendiri. Islam menjadi diragukan sebagai sebuah agama, Nabi Muhammad diberi label sebagai seorang penjahat, teroris dan lain sebagainya. Kebenaran Islam semakin diragukan. Islamofobia kini berhasil membentuk persepsi buruk terhadap Islam. Katakata seperti biadab, tidak beradab, kejam, otoriter terus digunakan untuk menggambarkan keyakinan dari Muslim dan praktek budayanya. ${ }^{5}$

Dalam hal ini media diyakini menjadi salah satu platform yang memicu terbentuknya stereotip ini. Banyak didapati media-media yang memberikan gambaran kesenjangan realitas yang dapat mempengaruhi opini publik dan diterima mentah-mentah oleh khalayak umum. Distorsi informasi yang identik menyebut Islam sebagai teroris, agama yang agresif, fundamentalis, militan dan sangat fanatik membentuk opini masyarakat sehingga kesalahpahaman dalam menerima informasi menciptakan pembusukan terhadap citra Islam di mata dunia. ${ }^{6}$ Tertuju pada media-media Barat yang terus memberikan gambaran negatif terhadap Umat Muslim dan selalu mendoktrin dengan anggapan bahwa Islam adalah salah satu bentuk ancaman yang nyata diyakini

\footnotetext{
${ }^{3}$ Kazeem Oluwaseun Dauda. (2020). "Islamofobia And Religious Intolerance : Threats To Global Peace And Harmonious Co-Existence." Qudus International Journal of Islamic Studies (QIJIS). Vol.8 , No. 2, Pages : 257 -292DOI : 10.21043/qijis.v8i2.6811.

${ }^{4}$ Rio Febriannur Rachman, (2018). Perspektif Karen Armstrong Tentang Islamofobia Di Media Barat. Dakwatuna: Jurnal Dakwah dan Komunikasi Islam, 4(2), 289.

${ }^{5}$ Rūta Sutkutè. (2019). Media, stereotypes and Muslim representation: world after Jyllands-Posten Muhammad cartoons controversy. EUREKA: Social and Humanities, (6), 59-72.

${ }^{6}$ Jasafat, J. (2014). Distorsi Terhadap Islam. Jurnal Ilmiah Peuradeun, 2(2), 193.
}

Al Qalam: Jurnal Ilmiah Keagamaan dan Kemasyarakatan Vol. 16, No. 2 Maret - April 2022 
Anggi Putri, Hardi Alunaza, Desy Nur Shafitri, Annisa Ernianda : Peningkatan Eksistensi Budaya Islamofobia Dalam Kehidupan Masyarakat Korea Selatan (STudi Kasus : Tindakan Penolakan Masyarakat Setempat Terhadap Pembangunan Masjid)

akan mempertahankan persepsi Islamofobia itu sendiri hingga saat ini. Eksistensi Islamofobia mungkin tidak akan pernah pudar dan semakin banyak diterapkan oleh banyak negara sebelum media-media Barat merubah persepsi tersebut ke arah positif sehingga Islam mendapat kembali citranya sebagai agama yang cinta damai layaknya gambaran terhadap agama-agama lain di dunia.

Ketidaksukaan irasional terhadap Umat Islam kini juga mulai mencuat di Korea Selatan. Perkembangan Islamofobia terus mengalami peningkatan di negeri ginseng ini. Sejatinya jumlah Umat Muslim di Korea Selatan masih dapat dikatakan minoritas kecil, namun sifat asing dari agama Islam bagi mereka, kemudian banyaknya stereotip negatif serta ketakutan tertentu orang Korea terhadap Umat Islam membuat Eksistensi Islamofobia sebagai bentuk fobia dan sasaran kebencian umum terhadap salah satu minoritas di Korea Selatan ini terus mengalami peningkatan yang cukup signifikan dari waktu ke waktu. Bahkan Komisi Hak Asasi Manusia negara ini menyiratkan bahwa salah satu manifestasi dan xenofobia yang ditujukan kepada imigran di Korea adalah Islamofobia itu sendiri yang tidak jarang terkait dengan isu multikulturalisme di negara tersebut. $^{7}$

Jumlah mesjid yang ada di Korea saat ini sudah cukup banyak yaitu mencapai 15 Masjid yang tersebar di daerah-daerah Korea Selatan. Masjid Pusat berada di Seoul, sementara MesjidMesjid lain berada di berbagai daerah seperti Busan, Gwangju, Jeonju, Anyang, Asan, Paju, Daegu, Gimpo, Changwon, Daejeon, Jeju dan Bupyeong. ${ }^{8}$ Namun demikian, baru-baru ini di daerah Daegu tepatnya di wilayah yang cukup padat akan pemukiman didapati penolakan dari penduduk setempat akan pembangunan sarana Masjid karena pemberian izin untuk pembangunan Masjid tersebut dianggap tidak mempertimbangkan pendapat dari penduduk setempat. ${ }^{9}$

Permasalahan ini berujung kepada konflik berkepanjangan yang masih banyak di perbincangkan. Pandangan terhadap Korea Selatan yang sempat diyakini sebagai negara yang ramah akan Muslim salah satunya dapat dilihat dari perkembangan halal food kini mulai terbantahkan. Sebelum konflik penolakan pembangunan Masjid ini sudah banyak terlihat bahwa perlakuan dari penduduk setempat yang pada awalnya masih awam melihat wanita Muslim yang menggunakan Jilbab namun seiring berjalannya waktu hal tersebut sudah tidak dipermasalahkan lagi. Kemudian masyarakat utamanya para pedagang mulai memahami jika Muslim hanya

${ }^{7}$ Gi Yeon Koo. (2018). Islamofobia and the Politics of Representation of Islam in Korea. Journal of Korean Religions, 9(1), 162. https://www.jstor.org/stable/26594685

${ }^{8}$ Ibid, hal 168

${ }^{9}$ Shafaqna. A sit-in to revoke a Mosque construction permit in South Korea. En.shafaqna.com, diakses melalui A sit-in to revoke a Mosque construction permit in South Korea - International Shia News Agency (shafaqna.com) pada tanggal 06 Februari 2022 Pukul 11.12 WIB

Al Qalam: Jurnal Ilmiah Keagamaan dan Kemasyarakatan Vol. 16, No. 2 Maret - April 2022 
Anggi Putri, Hardi Alunaza, Desy Nur Shafitri, Annisa Ernianda : Peningkatan Eksistensi Budaya Islamofobia Dalam Kehidupan Masyarakat Korea Selatan (STudi Kasus : Tindakan Penolakan Masyarakat Setempat Terhadap Pembangunan Masjid)

memakan makanan halal, sehingga mereka berupaya untuk menyediakan makanan halal yang bahkan dilabeli tulisan "halal" dengan tujuan untuk memudahkan Umat Islam dalam membeli makanan yang mereka inginkan, hal ini secara tidak langsung juga menjadi pusat wisata bagi Muslim-Muslim yang berwisata ke Korea Selatan. Dari hal itu didapat suatu argumentasi bahwa Umat Islam dapat jalan berdampingan dengan penduduk setempat jika dilihat dari penerimaan mereka melalui beberapa hal yang telah mereka pahami dari budaya-budaya Umat Islam. Akan tetapi konflik yang baru-baru ini terjadi membuat perubahan pandangan baik ke buruk oleh masyarakat internasional utamanya negara-negara dengan mayoritas pemeluk Islam terhadap Korea Selatan yang melakukan diskriminasi dan melanggar hak kebebasan beragama bagi Umat Islam.

Penulisan ini berusaha untuk menganalisis jawaban yang dibutuhkan oleh dari pertanyaan penelitian mengenai perkembangan Islamofobia di Korea Selatan. Penulis akan mencoba melihat bagaimana sentimen dan eksistensi perkembangan Islamofobia di Korea Selatan khususnya melalui satu studi kasus yaitu penolakan dari penduduk setempat di daerah Daegu akan pembangunan Masjid sebagai sarana untuk beribadah bagi Umat Islam. Argumen utama dalam penulisan ini adalah bahwa pada dasarnya eksistensi Islamofobia mulai menjadi budaya barat yang diterapkan oleh warga negara Korea Selatan terhadap Umat Islam di daerah mereka. Sehingga dari hal ini dapat dinyatakan melalui studi kasus yang diteliti bahwa eksistensi Islamofobia di Korea Selatan mengalami suatu peningkatan. Penulis berusaha menarasikan fenomena terkait Islamofobia yang terjadi di Korea Selatan, dan melihat bagaimana interaksi sosial yang terjadi antara masyarakat anti-Muslim dengan masyarakat Muslim di Korea. Selain itu penulis akan menjabarkan variabel yang menjadi penyebab fenomena tersebut tetap eksis bahkan mengalami peningkatan. Artikel ini akan melihat bagaimana sentimen Islamofobia dengan menjabarkan spektrum-spektrum yang berkaitan dengan peningkatan Islamofobia di Korea Selatan.

\section{Pluralisme Agama}

Pluralisme agama adalah salah satu isu yang mendapat perhatian yang cukup besar di sepanjang waktu. Perbedaan agama menjadi realitas yang paling sensitif karena setiap agama memiliki klaim absolut yang menyatakan bahwa tidak ada agama selain agamanya yang memiliki ajaran paling benar diantara semua agama, dan bahkan setiap sekte di dalam agama tersebut juga meyakini klaim ini. Hal ini yang pada dasarnya membuat diskursus pluralisme menjadi lebih kompleks sehingga memunculkan sejumlah teori yang pada dasarnya memberikan kesetaraan legitimasi terhadap setiap agama yang ada agar dalam tatanan kehidupan, setiap pemeluk agama

Al Qalam: Jurnal Ilmiah Keagamaan dan Kemasyarakatan Vol. 16, No. 2

$$
\text { Maret - April } 2022
$$


Anggi Putri, Hardi Alunaza, Desy Nur Shafitri, Annisa Ernianda : Peningkatan Eksistensi Budaya Islamofobia Dalam Kehidupan Masyarakat Korea Selatan (STudi Kasus : Tindakan Penolakan Masyarakat Setempat Terhadap Pembangunan Masjid)

yang berbeda dapat hidup damai secara berdampingan dengan toleransi yang tinggi dan saling menghargai antara satu dengan yang lainnya. ${ }^{10}$

Menurut Nurcholis Madjid, pluralisme agama dapat dikaji melalui tiga sikap agama. Pertama, sikap eksklusif dalam memandang agama lain yaitu dengan melihat bahwa mereka mengambil jalan yang salah dan menyesatkan umat. Kedua, sikap inklusif yaitu memandang agama lain atau bentuk implisit agama mereka. Ketiga, sikap pluralis yaitu sikap yang melihat agama lain adalah jalan yang sama-sama sah untuk mencapai kebenaran yang sama pula. Sikap ketiga memandang bahwa agama lain tidak apa berbicara atau memiliki ajaran yang berbeda namun kebenaran yang ingin dicari sama-sama sah. ${ }^{11}$ *Pluralisme agama juga dikatakan sebagai tindakan untuk saling menghargai, menghormati dan mengerti perbedaan-perbedaan antar umat beragama untuk mencapai kehidupan yang rukun dan terjauh dari konflik.

\section{METODE PENELITIAN}

Penelitian ini dilakukan dengan menggunakan metode penulisan deskriptif dan jenis penelitian kualitatif. Penelitian ini merujuk dari berbagai sumber literatur otoritatif terkait topik yang akan dibahas. Pengumpulan data menggunakan teknik dokumentasi. Sementara analisis yang digunakan adalah content analysis atau analisis isi.

\section{HASIL DAN PEMBAHASAN}

\section{Hadirnya Islam di Korea Selatan}

Korea Selatan dilihat secara historisnya, hidup berada di bawah pengaruh Shamanisme, Buddhisme, Taoisme dan Konfusianisme. ${ }^{12}$ Namun kemudian dalam perkembangan modern dan kemajuan globalisasi seiring dengan majunya teknologi dan transportasi berbagai agama termasuk Islam dan Kristen mulai memasuki Korea Selatan dan mengubah lanskap spiritual masyarakat tradisional menjadi lebih maju. Kemudian, pesatnya laju industrialisasi yang terjadi dalam beberapa dekade juga mendorong populasi penganut agama berkembang pesat, hal ini ditandai dengan munculnya lembaga-lembaga keagamaan organisasi sosial di kawasan Asia termasuk Korea Selatan.

${ }^{10}$ Anis Malik Thoha. (2005). Tren pluralisme agama: tinjauan kritis. Gema Insani.

${ }^{11}$ Jauharotul Munawaroh. (2012). Konsep Pluralisme Agama Dan Implikasinya Dalam Pendidikan Islam Studi Analisis Pemikiran KH.Abdurrahman Wahid. Skripsi. Semarang : Institut Agama Islam Negeri Walisongo

${ }^{12}$ Muhammad Nuh Hasan. (2017). Peran kelompok Sel Yonggi Cho dalam perkembangan gereja pantekosta di Korea Selatan. BS thesis. UIN Syarif Hidayatullah Jakarta: Fakultas Ushuluddin. hal 10-11.

Al Qalam: Jurnal Ilmiah Keagamaan dan Kemasyarakatan Vol. 16, No. 2

Maret - April 2022 
Anggi Putri, Hardi Alunaza, Desy Nur Shafitri, Annisa Ernianda : Peningkatan Eksistensi Budaya Islamofobia Dalam Kehidupan Masyarakat Korea Selatan (STudi Kasus : Tindakan Penolakan Masyarakat Setempat Terhadap Pembangunan Masjid)

Islam pertama kali diperkenalkan ke Semenanjung Korea pada abad ke-9 melalui pedagang Arab dan Persia. Mereka bertanggung jawab atas peta wilayah non-Asia Timur pertama yang digambar dan tulisan-tulisan perjalanan yang melibatkan petualangan mereka di Silla Bersatu. Sebagian besar pedagang ini berasal dari tempat yang sekarang disebut Irak, meskipun beberapa bukti arkeologis dari era ini menggambarkan penjaga istana Silla dengan karakteristik khas Persia. ${ }^{13}$ Mereka menetap dan menikah dengan komunitas lokal Korea, kemudian membangun komunitas yang akan bertahan selama beberapa abad berikutnya.

Islam di Korea telah muncul pada bulan September 1024, hal ini tertulis dalam catatan sejarah resmi Korea Selatan. Muslim memasuki Korea ketika para pedagang Arab memulai misi perdagangan besar menuju ke kerajaan Goryeo pada masa pemerintahan Raja Hyeonjong. Kejadian tersebut kemudian membukakan pintu bagi para pedagang dan migran Asia Tengah serta beberapa orang Muslim Hui China untuk menetap di Korea (Kerajaan Goryeo). Setelah pemindahan kekuasaan ke dinasti Yuan, banyak populasi Muslim permanen didirikan, salah satunya dengan pembuatan masjid yang dikenal sebagai Ye-kung, atau "ruang upacara". Dua dari pemukim ini akhirnya menjadi pendiri dua klan keluarga, termasuk Jang, yang kemudian menjadi pejabat tinggi pemerintah dengan monarki Goryeo dan Joseon. ${ }^{14}$

Sejak kemunculan dinasti Joseon yang baru, Muslim di Korea menghilang dalam catatan sejarah selama berabad-abad, hal ini dilatarbelakangi oleh kemunculan undang-undang baru yang membatasi Umat Muslim mempraktekkan keislamannya. Undang-undang yang dibuat oleh Raja Sejong pada tahun 1427 meminta agar Umat Muslim melepaskan tutup kepala, menutup Ye-kung (masjid pada masa itu) serta mematuhi norma yang terkandung dalam Konfusianisme. ${ }^{15}$

Muslim kembali muncul di Korea Selatan yaitu pada abad ke-19 ketika pemukim Korea bermigrasi ke Manchuria, saat itu Korea berada di bawah kebijakan kolonial Jepang. Selama perang Korea yang terjadi pada tahun 1950-1953, kontingen dari Turki membantu pertahanan Korea dan melakukan pekerjaan kemanusiaan untuk membangun kembali Korea. Setelah berakhirnya Perang Dunia II beberapa tentara ini tetap bertugas di Korea sebagai penjaga perdamaian PBB, pada kesempatan tersebutlah mereka mulai berdakwah hingga banyak masyarakat Korea memutuskan untuk mualaf. Para mualaf diizinkan untuk bergabung dengan layanan dari tentara Turki ketika melakukan ibadah. Hingga pada tahun 1955 dibentuklah Korea Muslim Society sebagai wadah pengukuhan Islam di Korea dan diikuti dengan pemilihan Imam

${ }^{13}$ Lee Hee-Soo. (1991). Early Korea-Arabic maritime relations based on Muslim sources. Korea Journal, 31(2). hlm 23

${ }^{14}$ Keith Pratt, and Richard Rutt. (2013). Korea: A historical and cultural dictionary. Routledge, hal. 189

${ }^{15}$ Don Baker. (2006). Islam Struggles for a Toehold in Korea. Harvard Asia Quarterly, 10(1).

Al Qalam: Jurnal Ilmiah Keagamaan dan Kemasyarakatan Vol. 16, No. 2

Maret - April 2022 
Anggi Putri, Hardi Alunaza, Desy Nur Shafitri, Annisa Ernianda : Peningkatan Eksistensi Budaya Islamofobia Dalam Kehidupan Masyarakat Korea Selatan (STudi Kasus : Tindakan Penolakan Masyarakat Setempat Terhadap Pembangunan Masjid)

Korea pertama. Masyarakat Islam Korea diperluas dan direorganisasi sebagai Korea Muslim Federation pada tahun 1967, dan sebuah masjid pusat didedikasikan di Seoul pada tahun $1976 .{ }^{16}$ Kini Islam semakin berkembang populasinya di Korea Selatan, bahkan wilayah pemukiman Muslim mulai meluas ke beberapa daerah seperti Busan, Jeonju, Gwangju, Daegu, Anyang dan Gyeonggi.

\section{Sentimen Islamofobia di Korea Selatan}

Dalam melihat kemungkinan sentimen Islamofobia yang ada di Korea Selatan, penting untuk melihat bagaimana pandangan umum terhadap Muslim dan Islam di seluruh dunia dan kejadian apa yang mendorong sentimen Islamofobia dan meningkatkan sikap anti-Muslim. Diketahui sejak adanya peristiwa 9/11 pada 2001 di gedung WTC serta kebangkitan ISIS pada 2014, sentimen terhadap Islamofobia dan permusuhan terhadap Muslim mengalami peningkatan. Peristiwa tersebut telah menyebabkan munculnya gelombang kejahatan dan kebencian terhadap Muslim di Amerika Serikat yaitu sebanyak 1600\% kejahatan yang terjadi pada tahun 2005 dan 2006 berdasarkan catatan U.S. Department of Justice. ${ }^{17}$ Dua kejadian ini meningkatkan citra negatif tentang Islam secara drastis, yang kemudian memberikan prasangka buruk, diskriminasi dan kebencian.

Korea Selatan umumnya terpapar media dan budaya Amerika yang didominasi oleh agama Kristen dimana masih memiliki bias psikologis terhadap Islam yang secara luas dianut oleh masyarakat di wilayah Timur Tengah. Berdasarkan survei yang dirilis oleh profesor Kim Su-wan di Hankuk University pada tahun 2016, masyarakat Korea memiliki gambaran Islam sebagai "terorisme, perang, konflik dan bahaya". ${ }^{18}$ Di Korea sendiri tidak ada peraturan khusus yang menjadi perlindungan hukum bagi minoritas Muslim sehingga memungkinkan untuk terjadinya diskriminasi terhadap Umat Muslim di sana.

Sentimen Islamofobia di Korea Selatan juga semakin meningkat setelah diperkenalkannya kebijakan halal pemerintah Korea pada tahun 2015. Dalam penelitiannya melalui Maydan, Ikran menjelaskan bahwa ketegangan dari gelombang Islamofobia ini semakin meningkat ketika pemerintah mengumumkan pembangunan Zona Halal di dalam National Food Cluster di kawasan Iksan, Provinsi Jeolla Utara di tahun 2015. ${ }^{19}$ Masyarakat Korea Selatan berpendapat

${ }^{16}$ Lilka Marino. (2015). A History of Islam in Korea. Korea Economic Istitute, diakses melalui https://keia.org/the-peninsula/a-history-of-Islam-in-korea/ pada 5 Februari 2022

${ }_{17}$ Jeffrey Kaplan. (2015). Islamofobia in America? September 11 and Islamophobic hate crime. In Radical religion and violence. Routledge. hal 306.

${ }^{18}$ Shin Ji-hye. (2021). [Us and Them] Islamofobia emerges in Korea. The Korea Herald, diakses melalui http://www.koreaherald.com/view.php?ud=20211004000082 pada 5 Februari 2022.

${ }^{19}$ Ikran Eum. (2019). Global Islamic Consumerism and Local Reactions: The Emergence of South Korea’s Halal Industry and Islamophobic Responses. Maydan, diakses melalui

Al Qalam: Jurnal Ilmiah Keagamaan dan Kemasyarakatan Vol. 16, No. 2

$$
\text { Maret - April } 2022
$$


Anggi Putri, Hardi Alunaza, Desy Nur Shafitri, Annisa Ernianda : Peningkatan Eksistensi Budaya Islamofobia Dalam Kehidupan Masyarakat Korea Selatan (STudi Kasus : Tindakan Penolakan Masyarakat Setempat Terhadap Pembangunan Masjid)

bahwa keuntungan dari industri halal akan mendukung kelompok teroris Muslim sehingga mereka meminta agar pemerintah tidak boleh mendukung agama tertentu dan mempertahankan posisi netralnya.

Lebih lanjut, Ikran dalam tulisannya mengatakan bahwa Korea Selatan memiliki tiga spektrum mengenai sentimen Islamofobia yang akan diuraikan sebagai berikut :

1. Spektrum pertama mengatakan bahwa Islamofobia di Korea Selatan dicirikan sebagai bentuk dari "Orientalisme yang direproduksi". Spektrum ini terlihat dari masyarakat Korea Selatan yang sering mengaitkan Islam dengan fanatisme agama, kebrutalan dan kekerasan, selain itu mereka juga memandang Muslim sebagai orang yang regresif, dilanda perang dan teror dan seksis atas elemen penindasan gender yang diwakili penggunaan kerudung yang dikenakan oleh wanita Muslim.

2. Spektrum kedua, Islamofobia Korea Selatan dinyatakan sebagai benturan peradaban antara agama Kristen yang berkonflik dengan Islam. Kristen yang memiliki 27,6 \% populasi dari total penduduk Korea Selatan, sedangkan Islam hanya memiliki populasi sekitar 200.000 jiwa yang kemudian tergolong sebagai kelompok minoritas. Namun, Islam justru memiliki perkembangan Industri halal yang meningkat sehingga Kristen memperspektifkannya sebagai ancaman.

3. Spektrum terakhir yaitu pandangan anti-Islam digunakan oleh kelompok-kelompok kepentingan yang berbeda untuk mendapatkan kekuasaan dan menggalang dukungan publik. Sebagai contohnya Partai Liberal Kristen melakukan kampanye pemilihan untuk Majelis Nasional 2016, berdasarkan platform anti-Islam dan melabeli Muslim sebagai teroris dan seksis.

Ketiga spektrum ini pada akhirnya meningkatkan sentimen Islamofobia di dalam masyarakat Korea Selatan. Hingga kini, sentimen ini terus berlanjut dan terus mendorong kebangkitan Islamofobia di negara Asia Timur ini.

\section{Implementasi Islamofobia Dalam Penolakan Pembangunan Masjid di Daegu}

Sentimen negatif dan pandangan penduduk Korea Selatan terhadap kebudayaan asing akhir-akhir ini akan menjadi perbincangan masyarakat dunia. Berdasarkan survei yang dilakukan oleh World Values Survey, tercatat sebanyak $44.2 \%$ orang Korea Selatan sulit menerima tetangga asing di lingkungan mereka. Hal ini memperlihatkan bagaimana tingginya hegemonitas masyarakat Korea Selatan. Tidak adanya keterlibatan pemerintah dalam mengatasi permasalahan diskriminasi di Korea Selatan khususnya Muslim. Pemerintah belum secara tegas menyatakan

https://themaydan.com/2019/03/global-Islamic-consumerism-and-local-reactions-the-emergence-of-southkoreas-halal-industry-and-Islamophobic-responses/ pada 6 Februari 2022.

Al Qalam: Jurnal Ilmiah Keagamaan dan Kemasyarakatan Vol. 16, No. 2

Maret - April 2022 
Anggi Putri, Hardi Alunaza, Desy Nur Shafitri, Annisa Ernianda : Peningkatan Eksistensi Budaya Islamofobia Dalam Kehidupan Masyarakat Korea Selatan (STudi Kasus : Tindakan Penolakan Masyarakat Setempat Terhadap Pembangunan Masjid)

hak-hak untuk orang asing dan minoritas di Korea Selatan sehingga masyarakat akan terus melakukan diskriminasi. ${ }^{20}$

Menurut survei terhadap 310 warga asing sebanyak 68,4 responden pernah mendapatkan diskriminasi rasial dari masyarakat sekitar. Data tersebut juga memperlihatkan alasan yang melatarbelakangi diskriminasi yang diterima diantaranya kurangnya kemampuan bahasa Korea mereka $(62,3 \%)$, bukan warga negara asli Korea $(59,7 \%)$, atau perbedaan ras mereka $(44,7 \%) .{ }^{21}$ Tingkat diskriminasi tinggi dan hegemonitas masyarakat yang kuat memperlihatkan bahwa sulit untuk membangun kebudayaan ataupun ajaran baru yang mampu berdampingan dengan kehidupan masyarakat Korea Selatan. Terlebih kepada Muslim yang sebelumnya telah memiliki citra sebagai 'terorisme' oleh sebagian masyarakat dunia yang phobia akan ajaran Islam.

Akhir-akhir ini bahkan diskriminasi terhadap Islam di Korea Selatan semakin meningkat. Sebelumnya akan ada proyek pembangunan masjid 2 lantai di Kota Daegu, Kota terbesar ketiga di Korea Selatan. Pembangunan masjid diusung oleh Komunitas Islam setempat yang mayoritas terdiri dari mahasiswa internasional di Universitas Nasional Kyungpook Daegu. Pembangunan masjid juga telah disetujui oleh Kantor Distrik Buk Daegu pada bulan September dan mulai dibangun pada Desember 2020. Pembangunan berlangsung lancar selama beberapa bulan, tiangtiang Masjid dan properti lainnya mulai dipasang namun tiba-tiba warga sekitar memberikan respons negatif terhadap pembangunan Masjid yang berada di tengah-tengah pemukiman mereka. ${ }^{22}$

Beberapa kelompok masyarakat dan kelompok Protestan konservatif di sekitar melakukan aksi penolakan dan unjuk rasa di depan lokasi pembangunan Masjid untuk pemberhentian proyek. Tidak hanya itu, mereka juga memasukkan surat petisi ke kantor distrik Daegu, meminta agar pemerintah segera mengakhiri pembangunan Masjid di daerah mereka karena alasan kebisingan dan pelanggaran hak milik warga. Tindakan tersebut memberikan pengaruh besar kepada perizinan pembangunan Masjid di Daegu. Sebab setelah beberapa bulan pembangunan, tepatnya pada bulan Februari otoritas distrik secara resmi mengeluarkan perintah administratif kepada

${ }^{20}$ Masnah Nurhadi. (2018). "Perilaku Diskriminasi Terhadap Orang Asing Di Korea Selatan.” Skripsi. Jakarata : Akademi Bahasa Asing Nasional.

${ }^{21}$ Ock Hyun-Ju. (2020). "7 in 10 Foreign Residents Say 'Racism Exists' in S.Korea." The Korea Herald. Diakses melalui http://www.koreaherald.com/view.php?ud=20200320000695 pada 6 Februari 2022 pukul 02.05

${ }^{22}$ Lee Hyo-Jin. (2021). "Backlash Growing Over Mosque Construction in Daegu." The Korea Times. Diakses melalui https://www.koreatimes.co.kr/www/nation/2021/09/281_315487.html pada 6 Februari 2022 pukul 04.11

Al Qalam: Jurnal Ilmiah Keagamaan dan Kemasyarakatan Vol. 16, No. 2

Maret - April 2022 
Anggi Putri, Hardi Alunaza, Desy Nur Shafitri, Annisa Ernianda : Peningkatan Eksistensi Budaya Islamofobia Dalam Kehidupan Masyarakat Korea Selatan (STudi Kasus : Tindakan Penolakan Masyarakat Setempat Terhadap Pembangunan Masjid)

pemilik gedung untuk menangguhkan proses pembangunan Masjid hingga batas waktu yang tidak bisa ditentukan..$^{23}$

Selain alasan karena mengganggu, kelompok penolak pembangunan Masjid mengatakan bahwa mereka tidak menyukai bau yang keluar dari pembangunan. Mereka juga khawatir jika kerumunan yang sering berdatangan akan memicu penyebaran korona semakin cepat dan takut daerah berubah menjadi lingkungan 'kumuh' tertinggal akibat pandangan orang-orang yang memandang daerah tersebut tempat "teroris dan kaum Muslim radikal. ${ }^{24}$ Warga khawatir jika harga properti di wilayah akan menurun sehingga akan sulit untuk membuat usaha dan pembangunan ke depannya. ${ }^{25}$ Penolakan masyarakat dalam pembangunan Masjid di Daegu mencerminkan bahwa budaya Islamofobia memang masih sangat terasa di Korea Selatan. Alasanalasan tidak masuk akal hanya untuk menentang pembangunan Masjid merupakan ketakutan akan penyebaran agama Islam di pemukiman mereka. Hal ini juga disampaikan oleh seorang warga yang memposting petisi di web Cheong Wa Dae dalam mendesak pemerintah untuk menjauhkan negara dari pengaruh Islam. Masyarakat mayoritas takut nantinya komunitas yang membangun properti (Masjid) akan memberikan pengaruh ajaran baru kepada penduduk setempat.

Meski diskriminasi terhadap Muslim terus berdatangan namun Muslim yang berada di Korea Selatan mulai menampakkan eksistensi mereka dengan menentang berita-berita buruk yang ditujukan kepada mereka. Komunitas Muslim Korea mulai bertindak terhadap kesalahpahaman dan diskriminasi yang diberikan. Sebelumnya Pada tanggal 18 Januari 2015 menjadi sejarah awal perlawanan masyarakat Muslim Korea Selatan kepada orang-orang yang mendiskriminasi mereka. Dilaporkan sebanyak 400 Muslim melakukan unjuk rasa di Distrik Itaewon, Seoul, Ibu Kota Korea Selatan dengan memegang tanda bertuliskan "Kami akan melanjutkan perang melawan fitnah." Meski ketengangan sempat terjadi di antara pejalan kaki polisi dan tentara, demonstrasi yang dilakukan berakhir dengan damai. ${ }^{26}$ Demonstrasi ini mendorong lebih banyak eksistensi komunitas Muslim di ruang Publik Korea. Muslim mulai berani untuk menampakkan identitas mereka di depan publik dan menjadi pembela aktif jika terdapat kesalahpahaman ke depannya.

\section{${ }^{23} \mathrm{Ibid}$.}

${ }^{24}$ VOI. (2021). "Mosque Construction Project In Daegu Suspended, South Korea's National Human Rights Commission : Irrational And Must Continue." VOI.ID. Diakses melalui https://voi.id/en/news/90545/mosque-construction-project-in-daegu-suspended-south-koreas-nationalhuman-rights-commission-irrational-and-must-continue pada 6 Februari 2022 pukul 06.15

${ }^{25}$ Nashih Nashrullah. (2021). "Islam di Korea Selatan, Tampak Damai Tapi Hadapi Islamofobia." Republika. Diakses melalui https://www.republika.co.id/berita/r0h5i9320/Islam-di-korea-selatan-tampakdamai-tapi-hadapi-Islamofobia-part1 pada 6 Februari 2022 pukul 06.30

${ }^{26}$ IkRan Eum. (2017). Korea's Response to Islam and Islamofobia : Focusing om Veiled Muslim Women's Experiences. Korea Observer. Vol.48 No.4 : 825-849

Al Qalam: Jurnal Ilmiah Keagamaan dan Kemasyarakatan Vol. 16, No. 2

$$
\text { Maret - April } 2022
$$


Anggi Putri, Hardi Alunaza, Desy Nur Shafitri, Annisa Ernianda : Peningkatan Eksistensi Budaya Islamofobia Dalam Kehidupan Masyarakat Korea Selatan (STudi Kasus : Tindakan Penolakan Masyarakat Setempat Terhadap Pembangunan Masjid)

Aktifnya gerakan Muslim di ruang publik Korea Selatan yang akhirnya mendorong komunitas Muslim Korea dan Komisi Nasional Hak Asasi Manusia Korea (NHRCK) untuk melawan tindakan pemberhentian pembangunan masjid di Daegu. NHRCK dibantu Komunitas Muslim Korea memberikan protes kepada kantor distrik atas pemberhentian sepihak yang dilakukan. NHRCK berpendapat bahwa Tuduhan yang diberikan warga sekitar tidak mendasar dan hanya prasangka kepada Umat Islam. ${ }^{27}$

Meski kantor distrik mendukung tindakan diskriminasi masyarakat dengan menyetujui pemberhentian Masjid namun Pengadilan Distrik Daegu memberikan respons yang berbeda. Pengadilan Daegu sempat memberikan dukungan untuk komunitas Islam agar membangun Pusat Islam Darul Emmann Kyungpook. Terkait pemberhentian pembangunan Masjid secara sepihak, Pengadilan berpendapat bahwa perintah yang diberikan Kantor Distrik memiliki kelemahan prosedural yang tidak biasa dan cenderung salah. Tidak ditemukan pembangunan yang melanggar Undang-undang konstruksi selama pengerjaan dilakukan sehingga perintah administratif yang dilakukan merupakan tindakan tanpa dasar hukum. Keputusan pengadilan tentu saja membantu pemilik dan komunitas Muslim untuk mempertahankan proyek pembangunan Masjid di Daegu. Meski pengadilan regional telah memutuskan untuk memulai kembali pembangunan namun kantor distrik Daegu belum menarik pernyataan pemberhentian Masjid sebelumnya. ${ }^{28}$

\section{KESIMPULAN}

Sentimen negatif dan pandangan sebagai kelompok minoritas membuat Muslim di Korea Selatan menerima tindakan diskriminasi baik di lingkungan sekitar rumah maupun pekerjaan. Pandangan masyarakat Korea Selatan yang melihat Muslim sebagai Fanatisme agama, brutal dan keras membuat sulitnya Muslim untuk berbaur di lingkungan mereka. Meski pada tahun 2015, pemerintah Korea Selatan telah mendukung kebijakan halal melalui makanan untuk meningkatkan kerja sama dengan negara-negara Muslim namun hal tersebut tidak dapat merubah pandangan masyarakat kepada Muslim. Mereka Khawatir untuk mendekat akibat stigma negatif sebagai kelompok terorisme dan kelompok Muslim Radikal. Begitu juga dengan kasus pemberhentian Masjid di Distrik Daegu, Korea Selatan, masyarakat memberikan ratusan petisi untuk pemberhentian proyek Masjid. Alasan dan kekhawatiran yang diberikan masyarakat seperti

\footnotetext{
${ }^{27}$ VOI. (2021). “Mosque Construction Project In Daegu Suspended, South Korea’s National Human Rights Commission : Irrational And Must Continue.” VOI.ID. Diakses melalui https://voi.id/en/news/90545/mosque-construction-project-in-daegu-suspended-south-koreas-nationalhuman-rights-commission-irrational-and-must-continue pada 6 Februari 2022 pukul 06.15

${ }^{28}$ Lee Hae-rin. (2021). "Court Rules Against Administrative Order to Halt Mosque Construction in Daegu.” Korea Times. Diakses melalui https://www.koreatimes.co.kr/www/nation/2021/12/281 319862.html pada 6 Februari 2022 pukul 07.28
}

Al Qalam: Jurnal Ilmiah Keagamaan dan Kemasyarakatan Vol. 16, No. 2 Maret - April 2022 
Anggi Putri, Hardi Alunaza, Desy Nur Shafitri, Annisa Ernianda : Peningkatan Eksistensi Budaya Islamofobia Dalam Kehidupan Masyarakat Korea Selatan (STudi Kasus : Tindakan Penolakan Masyarakat Setempat Terhadap Pembangunan Masjid)

takut harga properti menurun dan kawasan menjadi daerah 'kumuh' serta tertinggal hanya sebuah ketakutan akan membesarnya pengaruh Islam bagi masyarakat Korea Selatan, atau Islamofobia. Budaya Islamofobia bahkan semakin meningkat akibat perkembangan teknologi dan penyebaran isu-isu melalui media yang terkesan melebih satu peristiwa dan pada akhirnya memberikan citra tidak baik pada Muslim-Muslim di Korea Selatan.

\section{SARAN}

Pemerintah seharusnya memiliki andil besar dalam membantu pengurangan tindakan diskriminasi yang diterima masyarakat. Pemerintah dapat mengubah pandangan masyarakat terhadap minoritas utamanya yang berada di Korea Selatan dengan menciptakan Undang-undang yang lebih melindungi hak-hak minoritas di mana pun mereka berada. Pemerintah sendiri harus bersikap adil dan memperhatikan hak-hak seseorang tanpa meliat agama, budaya dan ras. Contohnya saat Kantor Distrik setuju untuk menghentikan pembangunan Masjid di Daegu. Seharusnya pemerintah mencabut “Kebijakan Diskriminatif” yang mereka lakukan, melihat tidak adanya pelanggaran khusus yang diperbuat saat proyek Masjid dibangun. Selain itu, pemerintah dapat bekerja sama dengan negara-negara Islam besar untuk mempromosikan Kebijakan Halal yang pemerintah Korea usung sebelumnya, dalam bentuk festival ataupun peringatan hari-hari besar. Tindakan saling mendukung antar pemerintah dan minoritas Muslim dapat membantu terbukanya pandangan masyarakat Korea Selatan bahwa Umat Islam bukanlah teroris dan penganut Radikal. Kemudian dalam kasus Islamofobia sendiri, Umat Islam seharusnya dapat lebih mengutuk tindakan-tindakan kekerasan yang dilakukan oleh pelaku-pelaku teror yang menggunakan label Islam. Hal ini diharapkan agar adanya perubahan pandangan dalam opini masyarakat luas bagaimana kebenaran Islam yang selama ini telah disalahpahami oleh dunia internasional.

Al Qalam: Jurnal Ilmiah Keagamaan dan Kemasyarakatan Vol. 16, No. 2

Maret - April 2022 
Anggi Putri, Hardi Alunaza, Desy Nur Shafitri, Annisa Ernianda : Peningkatan Eksistensi Budaya Islamofobia Dalam Kehidupan Masyarakat Korea Selatan (STudi Kasus : Tindakan Penolakan Masyarakat Setempat Terhadap Pembangunan Masjid)

\section{DAFTAR PUSTAKA}

Baker, Don. (2006). Islam Struggles for a Toehold in Korea. Harvard Asia Quarterly, 10(1).

Dauda, Kazeem Oluwaseun. (2020). "Islamofobia And Religious Intolerance : Threats To Global Peace And Harmonious Co-Existence." Qudus International Journal of Islamic Studies (QIJIS). Vol.8, No. 2, Pages : 257 -292DOI : 10.21043/qijis.v8i2.6811.

Eum, I. (2017). Korea's response to Islam and Islamofobia: Focusing on Veiled Muslim Women's Experiences. Korea Observer.Vol. 48 No.4 : 825-849.

Eum, Ikran. (2019). Global Islamic Consumerism and Local Reactions: The Emergence of South Korea's Halal Industry and Islamophobic Responses. Maydan, diakses melalui https://themaydan.com/2019/03/global-Islamic-consumerism-and-local-reactions-theemergence-of-south-koreas-halal-industry-and-Islamophobic-responses/ pada 6 Februari 2022.

Hasan, M. Nuh. (2017). Peran kelompok Sel Yonggi Cho dalam perkembangan gereja pantekosta di Korea Selatan. BS thesis. UIN Syarif Hidayatullah Jakarta: Fakultas Ushuluddin.

Hee-Soo, Lee. (1991). Early Korea-Arabic maritime relations based on Muslim sources. Korea Journal, 31(2), 21-32.

Hyo-Jin, Lee (2021). "Backlash Growing Over Mosque Construction in Daegu." The KoreaTimes. Diakses melalui https://www.koreatimes.co.kr/www/nation/2021/09/281 315487.html pada 6 Januari 2022 pukul 04.11

Jasafat, J. (2014). Distorsi Terhadap Islam. Jurnal Ilmiah Peuradeun, 2(2), 191-210.

Ji-hye, Shin. (2021). [Us and Them] Islamofobia emerges in Korea. The Korea Herald, diakses melalui http://www.koreaherald.com/view.php?ud=20211004000082 pada 5 Februari 2022.

Ju, Ock Hyun. (2020). 7 in 10 Foreign Residents Say 'Racism Exists' in S.Korea. The Korea Herald. Diakses melalui http://www.koreaherald.com/view.php?ud=20200320000695 pada 6 Februari 2022 pukul 2.05

Kaplan, Jeffrey. (2015). Islamofobia in America? September 11 and Islamophobic hate crime. In Radical religion and violence (pp. 292-329).

Koo, G. Y. (2018). Islamofobia and the Politics of Representation of Islam in Korea. Journal of Korean Religions, 9(1), 159-192. https://www.jstor.org/stable/26594685

Marino, Lilka. (2015). A History of Islam in Korea. Korea Economic Istitute, diakses melalui https://keia.org/the-peninsula/a-history-of-Islam-in-korea/ pada 5 Februari 2022.

Masduki, H. (2016). Pluralisme Dan Multikulturalisme Dalam Perspektif Kerukunan Antar Umat Beragama (Telaah Dan Urgensinya Dalam Sistem Berbangsa Dan Bernegara). DIMENSIJournal of Sociology, 9(1), 15-23.

Munawaroh, Jauharotul. (2012). Konsep Pluralisme Agama Dan Implikasinya Dalam Pendidikan Islam Studi Analisis Pemikiran KH.Abdurrahman Wahid. Skripsi. Semarang : Institut Agama Islam Negeri Walisongo

Al Qalam: Jurnal Ilmiah Keagamaan dan Kemasyarakatan Vol. 16, No. 2 Maret - April 2022 
Anggi Putri, Hardi Alunaza, Desy Nur Shafitri, Annisa Ernianda : Peningkatan Eksistensi Budaya Islamofobia Dalam Kehidupan Masyarakat Korea Selatan (STudi Kasus : Tindakan Penolakan Masyarakat Setempat Terhadap Pembangunan Masjid)

Nashrullah, Nashih (2021). "Islam di Korea Selatan, Tampak Damai Tapi Hadapi Islamofobia." Republika. Diakses melalui https://www.republika.co.id/berita/r0h5i9320/Islam-di-koreaselatan-tampak-damai-tapi-hadapi-Islamofobia-part1 pada 6 Februari 2022 pukul 06.30

Nurhadi, Masnah (2018). Perilaku Diskriminasi Terhadap Orang Asing Di Korea Selatan. Skripsi. Jakarata : Akademi Bahasa Asing Nasional.

Pratt, Keith, and Richard Rutt. (2013). Korea: A historical and cultural dictionary. Routledge, hal. 189. ISBN $\underline{0-7007-0464-7 .}$.

Rachman, R. F. (2018). Perspektif Karen Armstrong Tentang Islamofobia Di Media Barat. Dakwatuna: Jurnal Dakwah dan Komunikasi Islam, 4(2), 282-291.

Shafaqna. A sit-in to revoke a Mosque construction permit in South Korea. En.shafaqna.com, diakses melalui A sit-in to revoke a Mosque construction permit in South Korea - International Shia News Agency (shafaqna.com) pada tanggal 06 Februari 2022 Pukul 11.12 WIB.

Sutkutė, Rūta. (2019). Media, stereotypes and Muslim representation: world after Jyllands-Posten Muhammad cartoons controversy. EUREKA: Social and Humanities, (6), 59-72.

Thoha, A. M. (2005). Tren pluralisme agama: tinjauan kritis. Gema Insani.

VOI. (2021). "Mosque Construction Project In Daegu Suspended, South Korea's National Human Rights Commission : Irrational And Must Continue." VOI.ID. Diakses melalui https://voi.id/en/news/90545/mosque-construction-project-in-daegu-suspended-southkoreas-national-human-rights-commission-irrational-and-must-continue pada 6 Februari 2022 pukul 06.15

Al Qalam: Jurnal Ilmiah Keagamaan dan Kemasyarakatan Vol. 16, No. 2 Maret - April 2022 